\section{The Sound of Silence}

\author{
Ajahn Amaro ${ }^{1}$ \\ Published online: 25 August 2020 \\ (C) Amaravati Publications 2020
}

We can use many different methods, different objects, to support the focusing of our attention, for example, the rhythm of the breath or the feeling of our footsteps. But these are by no means the only tools available to us.

Most people who bring attention to their hearing and listen closely can discern a continuous, subtle, high-pitched ringing tone in the background. In Sanskrit, this is known as nada, which just means "sound." This inner sound is something to which we can pay attention, using its continuous, subtle, nonpersonal quality as an object of concentration. You can bring attention to it as an alternative to focusing on the breath. Just see if you can discern it. Listen inwardly. It is a "white noise" in the background of our listening - for some it might be quite loud, others might find it impossible to discern at all. Take a moment to listen. Bring attention to your hearing. See if you can perceive that sound.

This tone is also known as "the sound of silence." Over the years, it has been a regular theme in the teaching and practice of Luang Por Sumedho. For some people, the use of the sound of silence as a concentration object is a helpful and beneficial alternative to mindfulness of breathing. Sometimes it is easier to focus upon than the breath. It also has many qualities which lend a variety of helpful spiritual supports. Firstly, it does not begin or end. You never hear it start or stop. It is ever-present and continuous. It does not modulate according to your will, whereas the breath can be controlled. You can deliberately hold your breath, or breathe deeply or in a shallow way, but personal will has no effect on the sound of silence. You cannot make it do anything. It is just there-beginningless, endless, present.

Excerpted from The Breakthrough by Ajahn Amaro, Amaravati Publications, 2016.

Ajahn Amaro

ajahn.amaro@gmail.com

1 Amaravati Buddhist Monastery, Hemel Hempstead, Hertfordshire HP1 3BZ, UK
So in this way the sound of silence is a sense object which is a good symbol for the Dhamma itself: "Apparent here and now, timeless, encouraging investigation, leading inwards...." When you pay attention to it, it becomes obvious, but if you are caught up with other thoughts, activities, or conversations, the sound seems to disappear as if it had never been there. Thus, the nada sound is something "...to be experienced individually by the wise." In this way it possesses these suggestions of the quality of the Dhamma itself. It is a good symbol in the sense world of that which is transcendent - ultimate reality, the true Dhamma.

It also has a quality whereby if you concentrate on it, it helps to brighten the mind, and the brighter the mind is, the easier it is to listen to the sound. So there is a positive feedback loop. The more you pay attention to it, the easier it is paid attention to; accordingly, it leads to a greater quality of alertness, a keenness of attention. If we use this inner sound as an object to concentrate on, and consciously lay aside all other thoughts, preoccupations, sounds and physical sensations, the sound of silence is a very helpful and substantial support to samāahi. We can also use it to support the development of insight, the practice of vipassanā. In this latter case, we do not focus on it to the exclusion of everything else, but rather just let it be in the background, as a screen onto which all other experiences are projected. Even when you are speaking, you can still hear the nada sound in the gaps between the words. It is always here.

When we are aware of the sound in this way, it becomes the wallpaper of our inner space, the screen upon which thought and memory, feeling and sight, sound, smell, touch, and taste are projected. Letting the nada sound be in the background, yet still apprehended, helps to support a quality of nonentanglement with thought, feeling, memory, and our moods. In this case, the nada sound is an ever-present reminder of the context for all experiences, a reminder to us that this flow of perceptions is just the mind's representation of the world. The mind creates a world out of sights, sounds, sensations, smells, tastes, ideas, memories, moods, imaginings; but the everpresent nada sound in the background helps to remind us that these are just fleeting sense impressions, this is just a changing 
moment in the mind - a mood, a memory, an inspiration, a sorrow. It is what it is-just a pattern of this moment. So in this way, developing listening to the sound of silence directly supports the quality of insight. It helps us see the empty, selfless, uncertain, transient nature of all experience and patterns of consciousness.

The sound of silence is also helpful in developing attention and continuity of mindfulness. When the mind becomes very calm and focused, the breath can grow quieter and quieter. As we relax, the cycles of breath become slower and slower, so there can be long stretches of time between breaths - fifteen seconds, thirty seconds, a minute, a couple of minutes - even to the point where the breath seems to stop altogether. In these situations, if we are meditating on the breath, we find that the object of our meditation has disappeared. We no longer have access to the feeling of the breath if the breath is not moving. Very little if any sensation is associated with it. But the nada sound continues uninterrupted, ever-present regardless of the degree of concentration. Here it is - steady, unbroken, fluid like a constant silvery stream.

According to their conditioning, some people might not experience this energetic oscillation as a sound, but rather as a physical sensation: a corporeal vibration or a subtle quality of energy in the body, in the hands, the face, or the fingers. If we have developed a lot of body awareness, that is how we might pick up this universal vibration. Or someone who devotes a lot of attention to the visual world, a graphic artist for instance, might experience this vibration as a quality of the visual field, a continual subtle scintillation of the visual realm. However we experience it most strongly, that is the zone of perception we can use. That is the way in which it takes shape, so that is what we attend to.

It might also be that you have no idea what I'm talking about at all. You might be completely confused and have no sense of what this refers to. If that is the case and you cannot hear any kind of inner sound or feel any vibration, that's fine too. Just continue to use the breath as a primary object of awareness. The point is that we should work with the faculties and capacities which are available to us. We adapt the way that we work according to the means and situations open to us. The breath or the nada sound, or even applying the reflections on anicca, dukkha, anattā-all of these are just tools. The point is to end suffering. The point is to awakento know the quality of true peacefulness, to realize Nibbana. Perfecting the methods or applying the methods on their own is not the point, just as learning recipes or even learning how to cook is not the pointthe point is eating food and being nourished. It is not enough to be able simply to discern and attend to the sound of silence; the point is to learn to use it as a support for development of concentration and insight, using our meditation object as a context for developing the quality of wise reflection.
In our meditation during the day, whether it is sitting or walking, or as we go about our various activities, if we let the nada sound fill our awareness and allow it to be the background of our attention, when the mind is quiet and listening to the sound, we can drop in the question, "Who am I? Who is it that is aware?"

We listen to the silence, then just drop that question into it. And then wait.

Notice what quality of attention and awareness is present before any verbal or conceptual responses come into being.

Who am I?

What is it that is aware?

What knows this moment?

Who does this mind belong to?

Who does this moment belong to?

We can vary the question. We are not looking for particular conceptual answers, clever verbal answers, or standard Buddhist philosophical answers. We are using the question to help interrupt the habitual flow of self-creation. We are interrupting the habitual pattern of ahamkara mamamkara, I, me, mine-making. When there is hearing of the nada sound, what is it that knows that? What is it that knows the sound of your voice? Does this have an owner? What is it that is doing the owning? What can really own anything?

The point is not the question. We are not trying to create more confusion or complicated thinking. We are just dropping these reflective enquiries into the space of the mind. We drop these questions into the fertile silence and notice that interruption. Notice the silence. Listen to the silence before the question. Then: "Who am I?" Notice the mental space, the gap, immediately after the question has ended. Notice the space before the conceptual answers start to appear. Notice that hesitation, that pause. In that pause, self-creation is momentarily interrupted.

Bring attention to that pause, that gap, and sustain attention there as fully and completely as possible. Allow the attention to rest in that space, that opening.

When we carry out this kind of exercise, we listen to the silence, the inner sound. Once we are focused, we drop a question in-"What am I?" Clearly discern the qualities that are here. What is present just after the question is posed?

In the moment when the self-creation is interrupted, there are brightness, openness, peacefulness, and no sense of self. The habitual process of self-creation is broken up and trips over its own feet. For a moment, the camera is turned back on the photographer. Catch that moment. Notice that quality. Let the heart rest there. And when the attention gets snagged by thoughts and feelings, carried away by a sound we hear or an 
idea, bring the question up again: "What am I?" Reopen that space, as if you were parting the curtains.

After a while you might find that if you use the same question over and over, the mind becomes inured to it. It no longer has that opening effect. So we can move things round, be creative. Often we have to be quick on our feet, because the self-preservative habits are so strong, so pervasive, so determined to keep "me" in charge, "me" present, "me" running the whole thing. These "me" habits subtly undermine a particular question or statement and it loses its power. So we need to keep shifting it around, finding ways to prise that gap open, to part the curtains. You can be imaginative with this. The point is not the question that you ask, and certainly not any conceptual response, but rather the realization of the silence of the mind; the open, bright, clear, selfless mind which is revealed once the self-creating, self-obsessing habits are interrupted.

The silence of the mind is the answer to all questions.

Publisher's Note Springer Nature remains neutral with regard to jurisdictional claims in published maps and institutional affiliations. 